\title{
Fatigue - an underestimated symptom in psoriatic arthritis
}

\author{
Magdalena Krajewska-Włodarczyk ${ }^{1}$, Agnieszka Owczarczyk-Saczonek ${ }^{2}$, Waldemar Placek ${ }^{2}$ \\ ${ }^{1}$ Department of Rheumatology, The Nicolaus Copernicus Municipal Polyclinical Hospital, Olsztyn, Poland \\ 2Department of Dermatology, Sexually Transmitted Diseases and Clinical Immunology Clinic, University of Warmia and Mazury, \\ Olsztyn, Poland
}

\begin{abstract}
The nature of fatigue is very complex and involves physiological, psychological and social phenomena at the same time, and the mechanisms leading to occurrence and severity of fatigue are still poorly understood. The condition of chronic inflammation associated with psoriatic arthritis can be regarded as a potential factor affecting development of fatigue. Only a few studies so far have focused on the occurrence of fatigue in psoriatic arthritis. The problem of chronic fatigue is underestimated in everyday clinical practice. Identification and analysis of subjective fatigue components in each patient can provide an objective basis for optimal fatigue treatment in daily practice. This review presents a definition of chronic fatigue and describes mechanisms that may be associated with development of fatigue, highlighting the role of chronic inflammation, selected fatigue measurement methods and relations of fatigue occurrence with clinical aspects of psoriatic arthritis.
\end{abstract}

Key words: fatigue, inflammation, psoriatic arthritis.

\section{Introduction}

Fatigue, defined as a feeling of exhaustion, as well as reduced physical and mental capacity, is an important symptom accompanying many chronic diseases [1]. Structural and functional connections of motor, sensory and cognitive systems, incentive stimuli, and internal (homeostasis) and external environmental factors (e.g. temperature, humidity, noise) are responsible for normal physical fitness of the human body. Disorders at each stage of conducting, recognizing and processing of afferent and efferent impulses result in a feeling of excessive fatigue. Fatigue can be peripheral, which is associated with inability to maintain adequate strength and speed; and central, which is a consequence of unsuccessful initialization of the intended action and physical activity requiring self-motivation [2]. In terms of health, acute fatigue after physical or mental effort is a physiological mechanism leading to activity limitations in order to save energy. Chronic current fatigue in various autoimmune, cancerous and neurological diseases occurs regardless of undertaken physical activity and persists in the rest
$[3,4]$. Due to the complex nature and high subjectivity, fatigue as a symptom is difficult to assess objectively, and often remains misunderstood by patients' family or carers and neglected by physicians [5]. Individual feelings of fatigue associated with chronic diseases are also affected by personal factors: age, gender, employment, environment and social support. In the course of psoriasis and psoriatic arthritis, the prevalence and severity of fatigue are also related to the activity of inflammation, chronic pain, reduced physical fitness, sleeping disorders, decreased quality of life due to disease and emotional disorders, including anxiety and depressive reactions [6]. Intensity of fatigue varies significantly among chronically sick patients; however, many persons regard this symptom as one of the most troublesome [7].

\section{Inflammation in pathogenesis of fatigue}

Fatigue is often present in chronic inflammatory skin and joint diseases, systemic connective tissue diseases, cancer, infections, diabetes type I and other autoimmune diseases [4]. 
Production and secretion of cytokines regulating local and general immune responses are a consequence of immunological system activation. Cytokines, in addition to peripheral proinflammatory or anti-inflammatory effects, also have a signalling function in the central nervous system by neuronal and humoral activity. Proinflammatory cytokines can activate peripherally the vagus nerve and through the afferent fibres modulate brain activity [8], and can also activate the immuno-competent cells of microglia, located along blood vessels in circumventricular organs, where capillaries are fenestrated, resulting in an incomplete blood-brain barrier [9]. Microglia cells as a result of activation are capable of further production and secretion of cytokines. The cytokine effect in the brain spreads by diffusion, further activation of microglia cells and by projection neurons [10]. In modulation of neuron function by cytokines, the key mechanism is modification of monoaminergic nervous conduction occurring through activation of enzymes that disturb biosynthesis of dopamine and serotonin, such as guanosine triphosphate cyclohydrolase 1 (GTP-CH 1), associated with neopterin production, at the cost of tetrahydrobiopterin $(\mathrm{BH} 4)$ production, the basic cofactor in production of dopamine and serotonin $[11,12]$ and 2.3-dioxygenase indole (IDO), responsible for degradation of tryptophan in the kynurenic pathway resulting in a reduction of serotonin biosynthesis [13]. In addition, proinflammatory cytokines reduce dopamine and serotonin neurotransmission by limiting their synaptic availability $[14,15]$

The mechanism by which fatigue is caused in chronic diseases is multidimensional. Studies conducted among mice with colorectal cancer show that muscle weakness was not associated with changes in expression of myosin isoforms, or with deterioration of muscle contractility in tested animals. In addition, inclusion of anti-cancer treatment resulted in a decrease of interleukin $1 \beta$ (IL-1 $\beta)$ and IL- 6 in the brain, reduction of depressive symptoms and improvement of muscle strength without changes in muscle mass [16]. In another experiment on an animal model, application of proinflammatory IL-1 resulted in weak willingness to make social contacts, increased drowsiness and reduced body weight of animals, and these symptoms disappeared after anti-inflammatory injections: IL-1 receptor antagonist (IL-1RA) and IL-10 [17].

Research conducted on people has shown the relation of fatigue occurrence with presence of a coexisting inflammatory condition. In published studies on patients with myelodysplastic syndromes and acute myelogenous leukaemias, the severity of fatigue has been associated with an increase in serum concentration of proinflammatory cytokines - IL-6, tumour necrosis factor $\alpha$ (TNF- $\alpha$ ) and anti-inflammatory IL-1RA
[18] - whereas among patients with lung cancer it has been associated with an increased IL-8T-251A level [19]. Undoubtedly, occurrence of fatigue in these patients could be partly an adverse effect of cancer therapy; however, there are reports that describe severe fatigue in patients even 10 years after completion of treatment associated with high concentrations of C-reactive protein (CRP) and proinflammatory cytokines: IL-6 and IL-1RA [20, 21]. In other studies on people with chronic fatigue syndrome, an increase of IL-8 level, compared with a healthy control group [22] and examined soldiers with insomnia, was associated with higher concentrations of CRP in relation to measurements carried out after sleep disorders had disappeared [23]. Data from observation of patients with rheumatoid arthritis treated with biological agents that modify the course of illness, directed against TNF- $\alpha$, IL- 6 and antigenic CD-20, provide indirect evidence on the influence of inflammation in moderate to severe fatigue. Irrespective of applied therapy, all biological agents reduced fatigue accompanying illness [24]. However, in patients with hepatitis C undergoing immunotherapy based on interferon $\alpha$ (INF- $\alpha$ ) with a proinflammatory effect, severe fatigue occurred at the beginning of therapy, while mood disorders and cognitive function occurred in the late phase of treatment, which may also suggest a relation of inflammation with occurrence of fatigue [25].

It should be noted that fatigue accompanying chronic diseases depends not only on ongoing inflammation and its severity, but can also be a symptom associated with anaemia of chronic diseases, reduction of iron concentration associated with an increase in production of hepcidin induced by an increase in IL-6 level, decreased activity of the hypothalamic-pituitary-adrenal (HPA) axis, resistance to glucocorticoids and adverse effects of the therapy $[26,27]$.

\section{Fatigue assessment method in psoriatic arthritis}

Fatigue is a common symptom in chronic inflammatory diseases of joints and skin, even though it is rarely subjected to an evaluation in everyday clinical practice. There are no objective methods of measurement of the severity of fatigue associated with chronic diseases, and all available measuring instruments are based on self-assessment (Table I). The simplest and most often applied fatigue evaluation scale is a 100-mm horizontal visual analogue scale (VAS), which allows the patient to determine the severity by indicating the space between outermost points, where 0 indicates no fatigue, and 100 complete lack of strength and energy. The simplicity of measurement using the VAS is an undoubted advan- 
Table I. Selected self-reported fatigue scales

\begin{tabular}{|lcccc|}
\hline Scale & Aspects assessed & No. of questions & No. of subscales & Scale type \\
\hline $\begin{array}{l}\text { Visual Analogue Scale (VAS) [28] } \\
\text { unidimensional }\end{array}$ & Severity & 1 & 1 & Visual analogue \\
\hline $\begin{array}{l}\text { Medical Outcomes Study Short Form 36-item } \\
\text { scale (SF-36) [29] } \\
\text { multidimensional }\end{array}$ & Severity & 36 & 8 & $\begin{array}{c}\text { 3-6-point Likert, } \\
\text { yes/no }\end{array}$ \\
\hline $\begin{array}{l}\text { Multidimensional Assessment of Fatigue } \\
\text { (MAF) [30] } \\
\text { multidimensional }\end{array}$ & $\begin{array}{c}\text { Severity and } \\
\text { impact }\end{array}$ & 16 & 4 & 4-10-point Likert \\
\hline $\begin{array}{l}\text { Functional Assessment of Chronic Illness } \\
\text { Therapy Fatigue scale (FACIT-F) [31] } \\
\text { unidimensional }\end{array}$ & $\begin{array}{c}\text { Severity and } \\
\text { impact }\end{array}$ & 13 & 1 & 5-point Likert \\
\hline $\begin{array}{l}\text { Fatigue Severity Scale (FSS) [32] } \\
\text { unidimensional }\end{array}$ & $\begin{array}{l}\text { Impact and func- } \\
\text { tional outcomes }\end{array}$ & 9 & 1 & 7-point Likert \\
\hline
\end{tabular}

tage of this method [28]. Another test that is useful in measurement of fatigue in various chronic diseases, used also in persons with rheumatoid and skin diseases, is the 36-Item Short Form Health Survey (SF-36) Vitality Scale [29]. However, these methods do not include all aspects of fatigue. Questionnaires designed to evaluate fatigue in various diseases can also be used in patients with psoriasis and psoriatic arthritis. MAF (Multidimensional Assessment of Fatigue) contains questions to study four dimensions of fatigue: severity, mental fatigue, frequency and impact on everyday activity [30]. Another instrument for assessment of fatigue is the Functional Assessment of Chronic Illness Therapy - Fatigue Scale (FACIT-F), consisting of questions on general, physical, mental fatigue and the will to live [31]. In addition, the FACIT-F questionnaire was validated to estimate the fatigue associated with psoriatic arthritis [32]. Another assessment method used in research is based on the Fatigue Severity Scale (FSS), consisting of questions on the influence of fatigue in everyday function [33].

\section{Fatigue in psoriasis and psoriatic arthritis}

Psoriasis is a chronic skin disease of immune systems, occurring in approximately $2 \%$ of the population [34], which has a significant impact on the patient's life, especially in the case of progression of severe lesions [35]. Until recently, psoriasis as a disease was assessed only on the basis of the surface and clinical image of affected skin. However, recent studies have shown the relation of psoriasis severity with physical, emotional and social function [35, 36]. Psychosocial aspects of disease so far have been the subject of many studies [37-39], while the fatigue as a symptom that accompanies the disease was less often the subject of researchers' interest. Chronic fatigue associated with psoriasis may affect up to $50 \%$ of patients $[40,41]$, and up to $25 \%$ of all patients indicated the severity of fatigue as severe [41]. In the recently published study of Skoie et al., severity of fatigue was found to be associated with depression, pain and addiction to smoking, but, contrary to expectations, did not depend on the severity of psoriasis [40]. No association with the activity of disease evaluated with the Psoriasis Area Severity Index (PASI) was also described by Tobin et al.; however, fatigue rated as severe was twice as frequent in patients treated systemically than with phototherapy (appropriately 21\% vs. 11\%) [42].

Different results were presented by Verhoeven et al., who found a strong relation between evaluated fatigue and reduced quality of life associated with illness and with the evaluation of severity of the disease by patients. Here no relations of the occurrence of fatigue with coexistent diseases or demographic factors were observed, which indirectly indicates that fatigue could be determined by the presence and activity of underlying disease [41]. Occurrence of fatigue in patients with psoriasis may be associated with the presence of anxiety and other depressive symptoms [39, 42], and according to some researchers, it is more common in women than men [42]. Psoriatic skin lesions, especially active, cause local pain and itching, which lead to sleep disorders that clearly also affect the severity of fatigue [43]. There are limited data on the relation of psoriasis therapy with decreased feeling of fatigue. Most of the data concerning the effect of treatment on fatigue reduction in psoriasis was obtained in clinical research with biological agents, mainly with anti-tumour necrosis factor- $\alpha$. Infliximab, adalimumab, etanercept and ustekinumab significantly, according to patients, reduced fatigue while receiving the drug, also in re-administration of the drug in case of exacerbation after remission from withdrawal of the drug, while discontinuation was associated with severity of symptoms [43-53] (Table II). 
Table II. Selected studies of fatigue in patients with psoriasis treated with biologic agents

\begin{tabular}{|c|c|c|}
\hline Study (year) & $\begin{array}{l}\text { Fatigue } \\
\text { instrument }\end{array}$ & Outcomes \\
\hline $\begin{array}{l}\text { Krueger et al. [44] } \\
\text { (2005) }\end{array}$ & SF-36 & Etanercept reduced fatigue to a greater extent than placebo \\
\hline $\begin{array}{l}\text { Reich et al. [45] } \\
\text { (2006) }\end{array}$ & SF-36 & Infliximab reduced fatigue to a greater extent than placebo \\
\hline $\begin{array}{l}\text { Tyring et al. [46] } \\
\text { (2006) }\end{array}$ & FACIT-F & Fatigue decreased significantly following treatment with etanercept \\
\hline $\begin{array}{l}\text { Krishnan et al. [47] } \\
\text { (2007) }\end{array}$ & FACIT-F & Sustained reduction in fatigue for up to 96 weeks with etanercept \\
\hline $\begin{array}{l}\text { Daudén et al. [48] } \\
\text { (2009) }\end{array}$ & SF-36 & $\begin{array}{l}\text { Fatigue decreased significantly following continuous treatment with etanercept } \\
\text { versus paused therapy }\end{array}$ \\
\hline $\begin{array}{l}\text { Reich et al. [49] } \\
\text { (2009) }\end{array}$ & FACIT-F & $\begin{array}{l}\text { Fatigue was higher in patients with psoriasis than the population average and } \\
\text { approached the population norm after } 24 \text { weeks of etanercept treatment }\end{array}$ \\
\hline $\begin{array}{l}\text { Lebwohl et al. [50] } \\
\text { (2010) }\end{array}$ & SF-36 & Fatigue decreased significantly following treatment with ustekinumab \\
\hline $\begin{array}{l}\text { Papp et al. [51] } \\
\text { (2011) }\end{array}$ & FACIT-F & $\begin{array}{l}\text { Retreatment of adalimumab significantly reduced fatigue in patients who relapsed } \\
\text { after withdrawal of adalimumab }\end{array}$ \\
\hline $\begin{array}{l}\text { Nakagawa et al. [52] } \\
\text { (2012) }\end{array}$ & SF-36 & Ustekinumab reduced fatigue to a greater extent than placebo \\
\hline $\begin{array}{l}\text { Kalb et al. [53] } \\
\text { (2013) }\end{array}$ & SF-36 & Reduction of fatigue in non-responders to etanercept after switching to infliximab \\
\hline $\begin{array}{l}\text { Thaci et al. [43] } \\
\text { (2014) }\end{array}$ & FACIT-F & Fatigue decreased significantly following treatment with etanercept \\
\hline
\end{tabular}

In psoriatic arthritis, the frequency of observed fatigue, which is one of the main problems reported by patients and present in about $50 \%$ of patients, seems to be similar to psoriasis [6]. However, available studies show that fatigue occurring in patients with psoriatic arthritis is more severe than in people with psoriasis without inflammatory joint disease, and severe fatigue is present in approximately $30 \%$ of patients with psoriatic arthritis [6, 42]. Fatigue seems to be also one of the potential factors that predict development of psoriatic arthritis. In a recently published study on nonspecific symptoms prior to occurrence of arthritis associated with psoriasis, the severity of fatigue in patients with psoriasis was associated with higher risk of psoriatic arthritis development [54]. Physical disability and pain can increase the feeling of fatigue in patients with psoriatic arthritis [55], and additionally there have been described further significant associations of the presence and severity of fatigue with severity of psoriasis of the skin, reduced development level, as well as reduced number of painful joints and presence of enthesopathy [56]. Patients with psoriatic arthritis, regardless of place of residence and cultural factors, indicate that fatigue is the most often reported symptom after pain, even more acute than the degree of psoriatic skin lesions [56].
Fatigue therapy in psoriasis and psoriatic arthritis is based mainly on the treatment of underlying disease and non-pharmacological methods; however, even effective treatment reduces, but does not eliminate, fatigue $[43-53,57]$. It is necessary additionally to remember that fatigue can be associated with adverse effects of traditional medicines that modify the course of disease, such as methotrexate and leflunomide [58]. Antidepressant drugs are helpful in case of a depressive reaction increasing the feeling of fatigue [59]. Complementary therapeutic procedures can be drug-free methods to increase the motivation of patients in everyday physical activity and regular exercise while maintaining a balance between rest and exercise, education aimed to cope with stress and sleep hygiene [60].

\section{Conclusions}

The traditional approach to the treatment of psoriasis and psoriatic arthritis is often focused on reducing the inflammatory process, managing pain and treating organ complications, and relatively little attention is paid to the presence and severity of a symptom so frequent and important for patients as fatigue. Such an approach results from underestimating fatigue, which actually constitutes part of the clinical image of psoriasis and psoriatic arthritis, as an important medical 
problem. Fatigue as an expression of weakness and lack of motivation may lead to loss of employment, social isolation and decreased quality of life due to disease. Chronic inflammation associated with overproduction of proinflammatory cytokines may affect the presence of fatigue, and additionally chronic pain, dermal pruritus, depressed mood and sleep disturbance affect the severity of fatigue. However, the mechanisms on which the presence of fatigue in psoriasis and psoriatic arthritis depends are not well understood and require further multidirectional research. Chronic fatigue is a subjective symptom experienced by the patient. Many methods of fatigue self-assessment by patients, based on a visual analogue scale or detailed questionnaires, have also found application in evaluation of psoriasis and psoriatic arthritis, but are used more often in scientific research than everyday clinical practice.

The authors declare no conflict of interest.

\section{References}

1. Dupond JL. Fatigue in patients with rheumatic diseases. Joint Bone Spine 2011; 78: 156-160.

2. Boksem MA, Tops M. Mental fatigue: costs and benefits. Brain Res Rev 2008, 59: 125-139.

3. Nikolaus S, Bode C, Taal E, et al. Fatigue and factors related to fatigue in rheumatoid arthritis: a systematic review. Arthritis Care Res (Hoboken) 2013; 65: 1128-1146.

4. Norheim KB, Jonsson G, Omdal R. Biological mechanisms of chronic fatigue. Rheumatology (Oxford) 2011; 50: 1009-1018.

5. Poulson MJ. Not just tired. J Clin Oncol 2001; 19: 4180-4181.

6. Husted JA, Tom BD, Schentag CT, et al. Occurrence and correlates of fatigue in psoriatic arthritis. Ann Rheum Dis 2009; 68: 1553-1558.

7. Hewlett S, Cockshott Z, Byron M, et al. Patients' perceptions of fatigue in rheumatoid arthritis: overwhelming, uncontrollable, ignored. Arthritis Rheum 2005; 53: 697-702.

8. Konsman JP, Parnet P, Dantzer R. Cytokine-induced sickness behavior: mechanisms and implications. Trends Neurosci 2002; 25: 154-159.

9. Quan N, Banks WA. Brain-immune communication pathways. Brain Behav Immun 2007; 21: 727-735.

10. Vitkovic L, Konsman JP, Bockaert J, et al. Cytokine signals propagate through the brain. Mol Psychiatr 2000; 5: 604-615.

11. Murr C, Widner B, Wirleitner B, et al. Neopterin as a marker for immune system activation. Curr Drug Metab 2002; 3: 175-187.

12. Capuron L, Schroecksnadel S, Feart C, et al. Chronic low-grade inflammation in elderly persons is associated with altered tryptophan and tyrosine metabolism: role in neuropsychiatric symptoms. Biol Psychiatry 2011; 70: 175-182.

13. O'Connor JC, Andre C, Wang Y, et al. Interferon-gamma and tumor necrosis factor-alpha mediate the upregulation of indoleamine 2,3-dioxygenase and the induction of depressive-like behavior in mice in response to Bacillus Calmette-Guerin. J Neurosci 2009; 29: 4200-4209.
14. Moron JA, Zakharova I, Ferrer JV, et al. Mitogen-activated protein kinase regulates dopamine transporter surface expression and dopamine transport capacity. J Neurosci 2003; 23: 8480-8488.

15. Malynn S, Campos-Torres A, Moynagh P, et al. The pro-inflammatory cytokine TNF-alpha regulates the activity and expression of the serotonin transporter (SERT) in astrocytes. Neurochem Res 2013; 38: 694-704.

16. Norden DM, Bicer S, Clark Y, et al. Tumor growth increases neuroinflammation, fatigue and depressive-like behavior prior to alterations in muscle function. Brain Behav Immun 2014; 43: 76-85.

17. Bluthe RM, Beaudu C, Kelley KW, et al. Differential effects of IL-1ra on sickness behavior and weight loss induced by IL-1 in rats. Brain Res 1995; 677: 171-176.

18. Meyers CA, Albitar M, Estey E. Cognitive impairment, fatigue, and cytokine levels in patients with acute myelogenous leukemia or myelodysplastic syndrome. Cancer 2005; 104: 788-793.

19. Reyes-Gibby CC, Wang J, Spitz M, et al. Genetic variations in interleukin-8 and interleukin-10 are associated with pain, depressed mood, and fatigue in lung cancer patients. J Pain Symptom Manage 2013; 6: 161-172.

20. Irwin MR. Inflammation at the intersection of behavior and somatic symptoms. Psychiatr Clin North Am 2013; 34: 605-620.

21. Bower JE. Cancer-related fatigue: links with inflammation in cancer patients and survivors. Brain Behav Immun 2007; 21: 863-871.

22. Neu D, Mairesse O, Montana X, et al. Dimensions of pure chronic fatigue: psychophysical, cognitive and biological correlates in the chronic fatigue syndrome. Eur J Appl Physiol 2014; 114: 1841-1851.

23. Heinzelmann $\mathrm{M}$, Lee $\mathrm{H}$, Rak $\mathrm{H}$, et al. Sleep restoration is associated with reduced plasma C-reactive protein and depression symptoms in military personnel with sleep disturbance after deployment. Sleep Med 2014; 15: 1565-1570.

24. Chauffier K, Salliot C, Berenbaum F, et al. Effect of biotherapies on fatigue in rheumatoid arthritis: a systematic review of the literature and meta-analysis. Rheumatology (Oxford) 2012; 51: 60-68.

25. Capuron L, Castanon N. Role of inflammation in the development of neuropsychiatric symptom domains: evidence and mechanisms. Curr Top Behav Neurosci 2017; 31: 31-44.

26. Masson C. Rheumatoid anemia. Joint Bone Spine 2011; 78: 131-137.

27. Chrousos GP. The hypothalamic-pituitary-adrenal axis and immune-mediated inflammation. N Engl J Med 2010; 332: 1351-1362.

28. Wolfe F, Michaud K, Pincus T. Preliminary evaluation of a visual analog function scale for use in rheumatoid arthritis. J Rheumatol 2005; 32: 1261-1266.

29. Ware JE, Kosinski M, Keller SD. SF-36 Health Survey: Manual and Interpretation Guide. MA, USA: The Health Institute, New England Medical Center; 1983.

30. Belza BL, Henke CJ, Yelin EH, et al. Correlates of fatigue in older adults with rheumatoid arthritis. Nurs Res 1993, 42: 93-99.

31. Cella D, Yount S, Sorrensen M, et al. Validation of the Functional Assessment of Chronic Illness Therapy Fatigue Scale relative to other instrumentation in patients with rheumatoid arthritis. J Rheumatol 2005; 32: 811-819. 
32. Chandran V, Bhella S, Schentag C, et al. Functional assessment of chronic illness therapy-fatigue scale is valid in patients with psoriatic arthritis. Ann Rheumatic Dis 2007; 66: 936-939.

33. Krupp LB, LaRocca NG, Muir-Nash J, et al. The fatigue severity scale. Application to patients with multiple sclerosis and systemic lupus erythematosus. Arch Neurol 1989; 46: 1121-1123.

34. Langley RG, Krueger GG, Griffiths CE. Psoriasis: epidemiology, clinical features, and quality of life. Ann Rheum Dis 2005; 64: 18-23.

35. Meyer N, Paul C, Feneron D et al. Psoriasis: an epidemiological evaluation of disease burden in 590 patients. J Eur Acad Dermatol Venereol 2010; 24: 1075-1082.

36. Heller MM, Wong JW, Nguyen TV, et al. Quality-of-life instruments: Evaluation of the impact of psoriasis on patients. Dermatol Clin 2012; 30: 281-291.

37. Jankovic S, Raznatovic M, Marinkovic J, et al. Health-related quality of life in patients with psoriasis. J Cutan Med Surg 2011; 15: 29-36.

38. Armstrong AW, Schupp C, Wu J, et al. Quality of life and work productivity impairment among psoriasis patients: findings from the National Psoriasis Foundation survey data 20032011. PLoS One 2012; 7: e52935.

39. McDonough E, Ayearst R, Eder L, et al. Depression and anxiety in psoriatic disease: prevalence and associated factors. I Rheumatol 2014; 41: 887-896.

40. Skoie IM, Dalen I, Ternowitz T, et al. Fatigue in psoriasis - a controlled study. Br J Dermatol 2017; doi: 10.1111/bjd.15375.

41. Verhoeven EW, Kraaimaat FW, van de Kerkhof PC, et al. Prevalence of physical symptoms of itch, pain and fatigue in patients with skin diseases in general practice. $\mathrm{Br} J$ Dermato 2007; 156: 1346-1349.

42. Tobin AM, Sadlier M, Collins P, et al. Fatigue as a symptom in psoriasis and psoriatic arthritis: an observational study. $\mathrm{Br}$ J Dermatol 2016; doi: 10.1111/bjd.15258.

43. Thaci D, Galimberti R, Amaya-Guerra M, et al. Improvement in aspects of sleep with etanercept and optional adjunctive topical therapy in patients with moderate-to-severe psoriasis: results from the PRISTINE trial. J Eur Acad Dermatol Venereo 2014; 28: 900-906.

44. Krueger GG, Langley RG, Finlay AY, et al. Patient-reported outcomes of psoriasis improvement with etanercept therapy: results of a randomized phase III trial. Br J Dermatol 2005; 153 1192-1199.

45. Reich K, Nestle FO, Papp K, et al. Improvement in quality of life with infliximab induction and maintenance therapy in patients with moderate-to-severe psoriasis: a randomized controlled trial. Br J Dermatol 2006; 154: 1161-1168.

46. Tyring S, Gottlieb A, Papp K, et al. Etanercept and clinical outcomes, fatigue, and depression in psoriasis: double-blind placebo-controlled randomised phase III trial. Lancet 2006; 367: 29-35.

47. Krishnan R, Cella D, Leonardi C, et al. Effects of etanercept therapy on fatigue and symptoms of depression in subjects treated for moderate to severe plaque psoriasis for up to 96 weeks. Br J Dermatol 2007; 157: 1275-1277.

48. Daudén E, Griffiths CE, Ortonne JP, et al. Improvements in patient-reported outcomes in moderate-to-severe psoriasis patients receiving continuous or paused etanercept treatment over 54 weeks: the CRYSTEL study. J Eur Acad Dermatol Venereol 2009; 23: 1374-1382.

49. Reich K, Segaert S, Van de Kerkhof P, et al. Once-weekly administration of etanercept $50 \mathrm{mg}$ improves patient-reported outcomes in patients with moderate-to-severe plaque psoriasis. Dermatology 2009; 219: 239-249.

50. Lebwohl M, Papp K, Han C, et al. Ustekinumab improves health-related quality of life in patients with moderate-to-severe psoriasis: results from the PHOENIX 1 trial. Br J Dermatol 2010; 162: 137-146.

51. Papp K, Crowley J, Ortonne JP, et al. Adalimumab for moderate to severe chronic plaque psoriasis: efficacy and safety of retreatment and disease recurrence following withdrawal from therapy. Br J Dermatol 2011; 164: 434-441.

52. Nakagawa $H$, Schenkel B, Kato $M$, et al. Impact of ustekinum$\mathrm{ab}$ on health-related quality of life in Japanese patients with moderate-to-severe plaque psoriasis: results from a randomized, double blind, placebo-controlled phase 2/3 trial. J Dermatol 2012; 39: 761-769.

53. Kalb RE, Blauvelt $A$, Sofen $H L$, et al. Effect of infliximab on health-related quality of life and disease activity by body region in patients with moderate-to-severe psoriasis and inadequate response to etanercept: results from the PSUNRISE trial. J Drugs Dermatol 2013; 12: 874-880.

54. Eder L, Polachek A, Rosen CF, et al. The development of PsA in patients with psoriasis is preceded by a period of non-specific musculoskeletal symptoms: A prospective cohort study. Arthritis Rheumatol 2017; 69: 622-629.

55. Husted JA, Tom BD, Farewell VT, et al. Longitudinal analysis of fatigue in psoriatic arthritis. J Rheumatol 2010, 37: 1878-1884.

56. Gudu T, Etcheto A, de Wit M, et al. Fatigue in psoriatic arthritis a cross-sectional study of 246 patients from 13 countries. Joint Bone Spine 2016; 83: 439-443.

57. Strand V, Singh JA. Improved health-related quality of life with effective disease-modifying antirheumatic drugs: evidence from randomized controlled trials. Am J Manag Care 2007; 13 : 237-251.

58. Singh H, Arya S, Talapatra P, et al. Assessment of fatigue in rheumatoid arthritis (by Functional Assessment of Chronic Illness Therapy-Fatigue score) and its relation to disease activity and anemia. J Clin Rheumatol 2014; 20: 87-90.

59. Vincent A, Benzo RP, Whipple MO, et al. Beyond pain in fibromyalgia: insights into the symptom of fatigue. Arthritis Res Ther 2013; 15: 221

60. Repping-Wuts $H$, van Riel P, van Achterberg T. Rheumatologists' knowledge, attitude and current management of fatigue in patients with rheumatoid arthritis (RA). Clin Rheumatol 2008; 27: 1549-1555. 